\title{
Retention of HIV infected pregnant and breastfeeding women on option B+ in Gomba District, Uganda: a retrospective cohort study
}

George Kiwanuka ${ }^{1 *}$ (D), Noah Kiwanuka², Fiston Muneza², Juliet Nabirye ${ }^{1}$, Frederick Oporia ${ }^{3}$, Magdalene A. Odikro², Barbara Castelnuovo ${ }^{4}$ and Rhoda K. Wanyenze ${ }^{3}$

\begin{abstract}
Background: Lifelong antiretroviral therapy for HIV infected pregnant and lactating women (Option B+) has been rapidly scaled up but there are concerns about poor retention of women initiating treatment. However, facilitybased data could underestimate retention in the absence of measures to account for self-transfers to other facilities. We assessed retention-in-care among women on Option B+ in Uganda, using facility data and follow-up to ascertain transfers to other facilities.

Methods: In a 25-month retrospective cohort analysis of routine program data, women who initiated Option B+ between March 2013 and March 2015 were tracked and interviewed quantitatively and qualitatively (in-depth interviews). Kaplan Meier survival analysis was used to estimate time to loss-to-follow-up (LTFU) while multivariable Cox proportional hazards regression was applied to estimate the adjusted predictors of LTFU, based on facility data. Thematic analysis was done for qualitative data, using MAXQDA 12. Quantitative data were analyzed with STATA ${ }^{\oplus} 13$.

Results: A total of 518 records were reviewed. The mean (SD) age was 26.4 (5.5) years, 289 women (55.6\%) attended primary school, and 53\% (276/518) had not disclosed their HIV status to their partners. At 25 months post-ART initiation, 278 (53.7\%) were LTFU based on routine facility data, with mean time to LTFU of 15.6 months. Retention was 60.2 per 1000 months of observation (pmo) $(95 \%$ Cl: 55.9-64.3) at 12, and 46.3/1000pmo (95\% Cl: 42.0-50.5) at 25 months. Overall, 237 (55\%) women were successfully tracked and interviewed and 43/118 (36.4\%) of those who were classified as LTFU at facility level had self-transferred to another facility. The true 25 months post-ART initiation retention after tracking was 71.3\% (169/237). Women < 25 years, aHR $=1.71$ (95\% Cl: 1.28-2.30); those with no education, aHR $=5.55$ (95\% Cl: $3.11-$ 9.92), and those who had not disclosed their status to their partners, aHR $=1.59$ (95\% Cl: 1.16-2.19) were more likely to be LTFU. Facilitators for Option B+ retention based on qualitative findings were adequate counselling, disclosure, and the desire to stay alive and raise HIV-free children. Drug side effects, inadequate counselling, stigma, and unsupportive spouses, were barriers to retention in care.

Conclusions: Retention under Option B+ is suboptimal and is under-estimated at health facility level. There is need to institute mechanisms for tracking of women across facilities. Retention could be enhanced through strategies to enhance disclosure to partners, targeting the uneducated, and those $<25$ years.
\end{abstract}

Keywords: EMTCT, PMTCT, Retention, LTFU, HIV, Option B+

\footnotetext{
*Correspondence: georgekiwa@gmail.com

'Department of Health Policy Planning and Management, Makerere

University School of Public Health, P.O Box 7072, Kampala, Uganda

Full list of author information is available at the end of the article
}

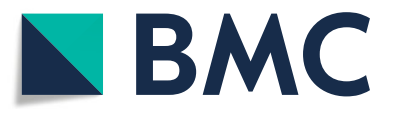

(c) The Author(s). 2018 Open Access This article is distributed under the terms of the Creative Commons Attribution 4.0 International License (http://creativecommons.org/licenses/by/4.0/), which permits unrestricted use, distribution, and reproduction in any medium, provided you give appropriate credit to the original author(s) and the source, provide a link to the Creative Commons license, and indicate if changes were made. The Creative Commons Public Domain Dedication waiver (http://creativecommons.org/publicdomain/zero/1.0/) applies to the data made available in this article, unless otherwise stated. 


\section{Background}

Progress against HIV/AIDS over the last 15 years has inspired the global commitment to eliminate mother-tochild transmission of HIV (eMTCT) by 2020 [1], and the HIV epidemic by 2030 [2]. Since 1995, an estimated 1.6 million new HIV infections amongst children have been prevented due to the provision of antiretroviral medicines to women living with HIV during pregnancy or breastfeeding. Despite this achievement, many children are still being infected, and dying from AIDSrelated illnesses [2].

Mother to child transmission (MTCT) of HIV is defined as the transmission of HIV from an HIV positive mother to her child during pregnancy, labor, delivery or breastfeeding [3]. In June 2013, the World Health Organization (WHO) recommended initiation of antiretroviral therapy (ART) for all pregnant and breastfeeding women with HIV, and continuation of ART for life (Option B+) [4]. Uganda started Option B+ rollout in December 2012. Gomba district was among the first districts to implement Option $\mathrm{B}+[5]$ and had scaled up services to all levels of health facilities by the time this study was conducted. At District level, the Uganda Primary Health care system has four levels of care, including Health Center II, III, IV, and District Hospital. Health center II represents the first level of interface between the formal health sector and the communities and provides only ambulatory services. HC III offers continuous basic preventive, promotive and curative services, with provisions for laboratory services for diagnosis, and maternity care. HC IV provides all the above services including laboratory and comprehensive emergency obstetric services. The district hospital is the referral facility at district level offering specialized services [6].

Retention-in-care along the PMTCT cascade is an important indicator for quality of PMTCT services and a determinant of PMTCT outcomes [7, 8]. Retention-in-care is defined by the WHO as continuous engagement from diagnosis in a package of prevention, treatment, support and care services [9]. Poor retention-in-care is one of the leading causes of virologic failure, drug resistance, and MTCT [10].

It is therefore important that PMTCT retention-in-care is clearly defined, accurately estimated, and its causes identified and addressed. However, many studies and evaluations that are based on facility data do not accurately estimate retention as they may not account for women who self-transfer to another health facility [11-14]. Without accounting for women who transfer to other facilities, retention-in-care may be under-estimated [15], and the extent of this under-estimation may vary based on the functionality of the referral mechanisms and tracking of patients across facilities. Studies that have attempted to address these gaps have had a short follow-up period and may not show the potential variations in retention during pregnancy, breastfeeding and after cessation of breastfeeding [16]. Further, the underlying barriers to retention have not been well-documented [17].

This study assessed retention-in-care in a 25-month cohort of pregnant and breastfeeding women on Option $\mathrm{B}+$ in Uganda, using facility based data and integrated follow-up to ascertain transfers to other facilities to fully account for retention of women in care. The study also integrated in-depth interviews to explain the outcomes for the women.

\section{Methods}

\section{Study setting and population}

We conducted this study in Gomba district, in central Uganda between May 01st and June 30th, 2017. Gomba is a rural district with $92 \%$ of the population rural [18]. The HIV seroprevalence in Gomba is at eight $8.0 \%$, higher than the national prevalence of 6.5\% [19] Almost all women in Gomba attend at least one antenatal care visit [20]. The study was a retrospective cohort analysis of routine program data, combined with a mixed methods cross-sectional study. The study population was pregnant and breastfeeding women who started Option B+ between March 2013 and March 2015. We included women who were residents of Gomba for over 6 months and excluded all those who were visitors.

\section{Data collection methods}

Four research assistants were trained to extract the data using a structured abstraction tool. Client charts were reviewed for 1,3,6,12,18 and 25 months attendance, along the eMTCT cascade. The eMTCT cascade is a series of important stepwise events that constitute a vital roadmap to successful eMTCT. The cascade begins with identification of HIV positive pregnant women and ends with the detection of a final HIV status in HIV-exposed infants at 18 months [21].

An attempt to track all the women from the cohort was made, using the telephone contacts and physical addresses of the women which were retrieved from their records. The research assistants called the women for either phone or face-to-face cross-sectional interviews.

A total of 12 in-depth interviews were conducted, with clients purposively selected, including six women that were retained in care at health facility level and six women who were categorized as LTFU. These were deemed sufficient for data saturation given the recurrent themes with no new emerging leads [22]. Two trained research assistants with experience in qualitative inquiry were employed. Potential participants were called 1 week prior to the interview date to schedule the interview. The in-depth interview guide was structured around predefined broad themes, with preset open ended 
questions focusing on lived experiences of women on Option B+.

The dependent variable was retention in care and LTFU. A mother was defined as retained in care if she returned to the health facility for care, within 60 days of her last scheduled clinic visit. From clinic ART dispensing records, this was the period estimated for a mother to have run out of drugs. Women who were out of care at the time of conducting the interviews (whether or not they had returned into care at any time during the follow-up period) were categorized as LTFU.

Prior to the data collection, the research assistants were trained, and the data collection tools, including the data abstraction tool and the interview questionnaire pilot tested. Daily feedback during the data collection period was received through meetings of the research assistants and the principal investigator, to review challenges and identify solutions.

\section{Sample size estimations and data analysis Sample size estimation}

The sample size was estimated using the online StatsTo-Do sample size calculator for survival analysis [23]. With a type one error $(\alpha)$ of 0.05 , power $(1-\beta)$ of 0.84 , survival rate in group 1 (SR1), which was the proportion of retention in care in adults receiving ART for health reasons (control group) of 0.87 [24], survival rate in group 2 (SR2), which is the anticipated proportion of retention under Option B+ (exposed group) of 0.69 [14], $r$ $=$ ratio of sample size in group $1 /$ sample size in group $2(\operatorname{ssiz} 1 / \operatorname{ssiz} 2)=(0.2)$, the total sample size was 232 women. However, we reviewed the records for all the women from all Health center II, III, and IV in the district that were enrolled in the 2-year period $(n=518)$, due to anticipated challenges of missing data.

\section{Statistical analysis}

Data were analyzed with STATA ${ }^{\bullet} 13$. During univariate analysis, a descriptive analysis was conducted to calculate the proportions of Option $\mathrm{B}+$ patients who died, stopped ART, were retained in care within the same health facility, and who self-transferred or were formally transferred to other facilities. Because our primary outcome is influenced by time along the Option B+ cascade, survival analysis method was used [14, 25]. The retention based on health facility records at 1, 3, 6, 12, 18 and 25 months after ART initiation was assessed using the Kaplan-Meir methods and survival functions were assessed over the 25-month period. The analysis was up to 25 months, because in our operational definition of retention, a mother was retained if she returned for care within 60 days of her scheduled visit, all those who were scheduled for 24 months reviews had until the end of 25 months to return for their visit. Bivariate analysis:
Log-rank test of equality was used, for categorical variables to examine the relationships of individual and facility related independent variables with retention. Cox proportional hazards regression analysis was used to analyze all the variables associated with retention, with a $p$-value of 0.05 .

For the qualitative data, audio tape recordings were simultaneously transcribed and translated verbatim from Luganda into English. Transcripts were then uploaded into the qualitative analysis software MAXQDA version 12 and data were analyzed following the six steps of thematic approach developed by Braun and Clarke [26].

\section{Results}

The study was conducted between 1st May and 30th June 2017. All the records of the 518 pregnant and breastfeeding women who were enrolled in care between March 2013 and March 2015 were included in the 25 -month retrospective cohort analysis. Of the 518 women, 237 (46\%) were successfully tracked for crosssectional interviews and ascertainment of retention status; 12 were selected for in-depth interviews (Fig. 1). Of the 518 women, 281 (54\%) were excluded because 234 (45\%) had no phone or residential contacts to enable tracking, 27(10.1\%) refused to speak to the interviewers on the phone or physically, and 20 had died.

Nearly half of the women, 234 (45\%) were enrolled into Option B+ in 2014, 209 (40.2\%) in 2013 and only 77 $(14.8 \%)$ in 2015 . Most of the women $(346 ; 67.2 \%)$ started ART during pregnancy while 95 (18.3\%) initiated ART before pregnancy, 7 (1.4\%) during labor and 68 (13.1\%) during breastfeeding. The women were aged between 16 and 48 years, with a mean age of 26.4 (SD: \pm 5 . 5). All the women delivered live babies, and $(379 ; 72.9 \%)$ had a DNA PCR test at 6 weeks (Table 1). Most of the women were enrolled at Health Center III, 353 (67.9\%) against 167 (32.1) that were enrolled at the Health Center IV. About half of the women 289 (55.6\%) had attended primary school, 141 (27.1\%) had post-primary education while 90 (17.3\%) had no formal education.

Of the 257 women who were tracked, 20 (7.8\%) had died. Among the remaining 237 who agreed to be interviewed, $161(62.7 \%)$ were in care, and $76(29.6 \%)$ not in care. Of the 237 women tracked, 131 (51\%) had been classified as LTFU and 126 (49\%) as retained, as per facility records. Following analysis of tracking data, true retention was found to be $71.3 \%(169 / 237)$. It was found that $36.4 \%(43 / 131)$ of those initially categorized as LTFU at facility level had not dropped out of care, but had simply self-transferred to another facility,

Using the log-rank test, prespecified subgroups were assessed to determine whether differences in retention at 25 weeks were dependent on participants' baseline clinical characteristics (Table 2). The overall rate of 


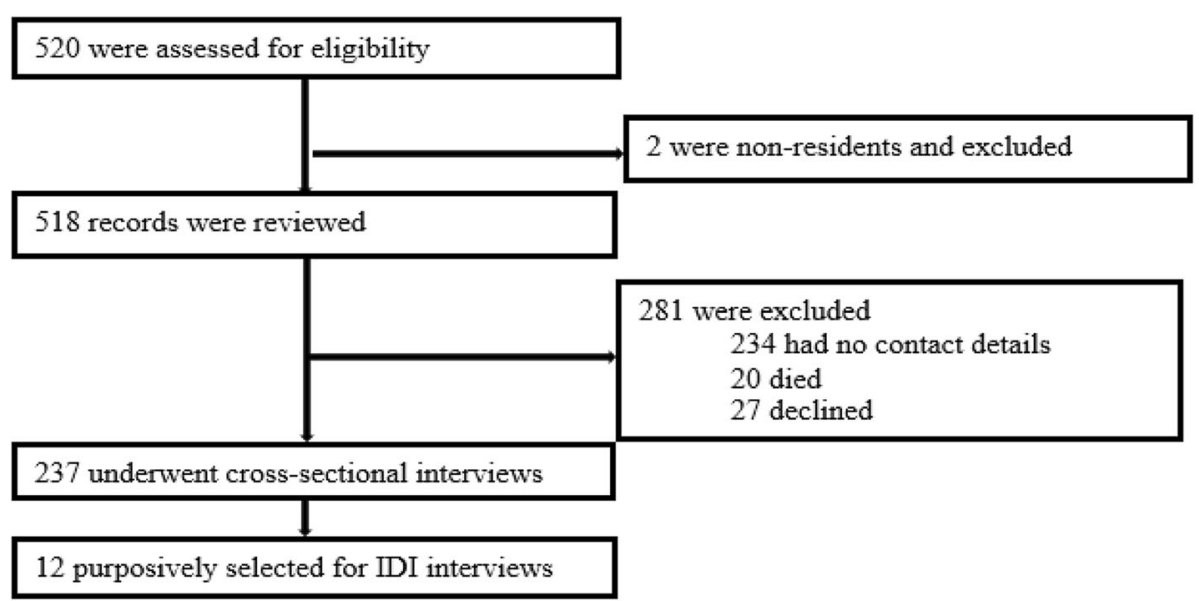

Fig. 1 Illustration of the study profile

health facility retention was $60.2 / 1000$ pmo (95\% CI: $55.9-64.3$ ) at 12 months and $46.3 / 1000$ pmo (95\% CI: $42.0-50.5)$ at 25 months.

As shown in Table 3, there were 518 observations at the start with total time at risk of 8080 months. The overall number of women LTFU by 25 months based on the facility data was 278 (53.7\%) translating into an overall incidence rate of LTFU of $30 / 1000$ pmo. The mean time to LTFU was 15.6 months, with a minimum exit time of 1 month and a maximum exit time of 25 months. The 25th percentile of the survival time was 3 months while the 50th percentile was 25 months.

The Kaplan-Meier method was used to estimate the retention curve from the observed times, using facility data. Overall, retention along the whole Option B+ cascade was poor, with the highest risk in the first 6 months (Fig. 2). Between 18 and 24 months, the critical period of transfer from Option B+ care point to General ART clinic, a considerable proportion of mothers were still lost.

Figure 3 shows a significant difference between the retention curve for those who disclosed from those who had not disclosed their HIV status. By 25 months post ART-initiation, about $65 \%$ of those who had disclosed their status to their partners were retained in care while only $35 \%$ of those who had not disclosed were retained $(\mathrm{p}=<0.001)$. Overall, non-disclosure of HIV status to spouse was associated with a risk of LTFU of about 35 percentage points higher than that associated with disclosure $(p=<0.001)$.

At multivariable analysis, women who were less than 25 years were more likely to be LTFU with adj.HR = 1.71; 95\% CI: $1.28,2.30$. Those with no education had highest chance of LTFU, aHR 5.55 (95\% CI: 3.11, 9.92), primary level of education had aHR 3.83 (95\% CI: 2.31, 6.33) in comparison with those who had attained post-primary education (Table 4). Non-disclosure of
HIV status was also significantly associated with LTFU, aHR 1.59 (95\% CI: 1.16, 2.19). Starting ART during pregnancy, and while breastfeeding was associated with higher chances of LTFU compared to for women who started ART before pregnancy 2.66 (95\% CI: $1.60,4.44)$.

Analysis of personal behavioral practices revealed that, difficulty in travelling to health facility, aHR 2.30 (95\% CI: 1.07, 4.92), and not receiving sufficient counselling, aHR 2.92 (95\% CI: 1.49, 5.72) before initiation of ART were the negative predictors of retention under attitudes and perceptions, while presence of peer mothers was a positive predictor (Table 5). Women who had difficulty in obtaining support from the spouse were nearly four times more likely to be LTFU, compared to those who obtained support from their spouses aHR 3.59 (95\% CI:2.21,5.81). Those who had difficulty in developing strategies to keep appointments were about two times more likely to be LTFU, aHR 1.89 (95\% CI: 1.17,3.05).

\section{Facilitators and barriers to retention in care for women on option $\mathrm{B}+$}

In-depth interviews for the women who were retained and those who were lost showed related issues, therefore, the arrangement of the results incorporates responses for both categories. The unique differences between the two categories are clearly emphasized during the description. Two major themes emerged from the analysis including initiation on Option $\mathrm{B}+$ and adherence to clinic visits/retention in care.

\section{Facilitators of option $\mathrm{B}+$ initiation}

All the women who were retained noted that disclosure, adequate partner counselling and support made their ART initiation ART very comfortable. 
Table 1 Baseline characteristics of the women from abstracted cohort data

\begin{tabular}{ll}
\hline Characteristic & $N=518(\%)$ \\
\hline Age & \\
$16-24$ & $220(42.3)$ \\
$25-48$ & $298(57.7)$
\end{tabular}

Education Level

None

90 (17.3)

$287(55.6)$

$141(27.1)$

Marital Status

Single

Married/Cohabiting

Separated/Divorced

Number of children

$$
\begin{aligned}
& 0-3 \\
& 4-5 \\
& 5+
\end{aligned}
$$

Health Facility Level

Health Center II/II

Health Center IV

Pregnancy Status at Enrollment

Pregnancy

Breastfeeding

Disclosure Status

$$
\begin{aligned}
& \text { No } \\
& \text { Yes }
\end{aligned}
$$

Period of starting ART

Before pregnancy

During Pregnancy

Labor

Breastfeeding

Place of Delivery

$$
\begin{aligned}
& \text { Home/TBA" } \\
& \text { Health Center level II/II }{ }^{\dagger} \\
& \text { Health Center level IV/Hospital } \\
& \text { Private Clinic }
\end{aligned}
$$

DNA-PCR at 6 weeks

Yes

No

Final Status of Child +

Negative

Positive

${ }^{\dagger}$ The final status of the child at 18 months is done using a rapid antibody test

\begin{tabular}{|c|c|c|c|}
\hline Characteristic & Retained, $N=119(\%)$ & LTFU, N=118(\%) & $P$-value \\
\hline \multicolumn{4}{|c|}{ Income/Monthly (Uganda Shilling) } \\
\hline$<50,000$ & $74(62.2)$ & $92(77.3)$ & \multirow[t]{3}{*}{0.0036} \\
\hline $50,001-100,000$ & $27(22.7)$ & $21(17.6)$ & \\
\hline$>100,000$ & $18(15.1)$ & $6(5.1)$ & \\
\hline \multicolumn{4}{|c|}{ Distance from Health Facility } \\
\hline$<1 \mathrm{~km}$ & $19(16.0)$ & $7(5.9)$ & \multirow[t]{3}{*}{$<0.001$} \\
\hline $1-5 \mathrm{~km}$ & $80(67.2)$ & $60(50.8)$ & \\
\hline$>5 \mathrm{~km}$ & $20(16.8)$ & $51(43.3)$ & \\
\hline \multicolumn{4}{|c|}{ Health Facility too far ${ }^{a}$} \\
\hline Disagree & $70(58.8)$ & $29(24.6)$ & \multirow[t]{2}{*}{$<0.001$} \\
\hline Agree & $49(41.2)$ & $89(75.4)$ & \\
\hline \multicolumn{4}{|c|}{ Difficulty in travelling to Health Facility ${ }^{a}$} \\
\hline Disagree & $70(58.8)$ & $29(24.6)$ & \multirow[t]{2}{*}{$<0.001$} \\
\hline Agree & $49(41.2)$ & $89(75.4)$ & \\
\hline \multicolumn{4}{|c|}{ Medicines available* } \\
\hline Disagree & $74(62.2)$ & $24(20.3)$ & \multirow[t]{2}{*}{0.8214} \\
\hline Agree & $45(37.8)$ & $94(79.7)$ & \\
\hline \multicolumn{4}{|c|}{ Counselling is sufficient ${ }^{a}$} \\
\hline Disagree & $0(0)$ & $34(28.8)$ & \multirow[t]{2}{*}{$<0.001$} \\
\hline Agree & $119(100)$ & $84(71.2)$ & \\
\hline
\end{tabular}
${ }^{\dagger}$ The Health center II/III are facilities that conduct deliveries but do not provide EMOC services

"Traditional birth attendants provide delivery services in the community, their services
Table 2 Showing demographic characteristics, perceptions and behavioral practices of women and the sub-group analysis for LTFU following cross-sectional interviews

Peer Mothers help at Option B+ initiation ${ }^{a}$

$\begin{array}{llll}\text { Disagree } & 6(5) & 32(27.1) & <0.001 \\ \text { Agree } & 113(95) & 86(72.9) & \end{array}$

Difficulty in handling daily hassles ${ }^{b}$

$\begin{array}{llll}\text { Disagree } & 85(71.4) & 51(43.2) & <0.001 \\ \text { Agree } & 34(28.6) & 67(56.8) & \end{array}$

Difficulty in developing strategies to manage appointments ${ }^{\text {b }}$

$\begin{array}{llll}\text { Disagree } & 100(84) & 44(37.3) & <0.001 \\ \text { Agree } & 19(16) & 74(62.7) & \\ \text { Difficulty in obtaining support from spouse } & & \\ \text { Disagree } & 80(67.2) & 24(20.3) & <0.001 \\ \text { Agree } & 39(32.8) & 94(79.7) & \end{array}$

I have confidence in the available HIV care system ${ }^{\mathrm{b}}$

$$
\begin{array}{lll}
\text { Disagree } & 0(0) & 6(5.1) \\
\text { Agree } & 119(100) & 112(94.9)
\end{array}
$$

Disclosed status to spouse?

$\begin{array}{llll}\text { No } & 37(31.1) & 83(70.3) & <0.001 \\ \text { Yes } & 82(68.9) & 35(29.7) & \end{array}$

andividual attitudes and perceptions about health care services

${ }^{b}$ Personal behavioral practices that influence health services utilization

"I really did not face many challenges when starting ARVs because I came to test with my husband, we had talked about the possible outcomes and we were ready 
Table 3 Probabilities of retention in Option B+ over a 24 months period

\begin{tabular}{|c|c|c|c|c|c|c|c|}
\hline Time (Months) & No. of women & LTFU & $\mathrm{Net}^{\mathrm{c}}$ Lost & Retention probability ${ }^{b}$ & $\mathrm{SE}^{\mathrm{a}}$ & $95 \% \mathrm{C}$ & \\
\hline 1 & 518 & 94 & 0 & 0.82 & 0.02 & 0.78 & 0.84 \\
\hline 3 & 424 & 42 & 0 & 0.74 & 0.02 & 0.69 & 0.77 \\
\hline 6 & 382 & 40 & 0 & 0.66 & 0.02 & 0.62 & 0.70 \\
\hline 12 & 342 & 30 & 0 & 0.60 & 0.02 & 0.56 & 0.64 \\
\hline 18 & 312 & 38 & 0 & 0.53 & 0.02 & 0.49 & 0.57 \\
\hline 25 & 274 & 34 & 240 & 0.46 & 0.02 & 0.42 & 0.51 \\
\hline
\end{tabular}

${ }^{\mathrm{a}} \mathrm{SE}$ stands for Standard error, $\mathrm{Cl}$, for Confidence intervals

${ }^{\mathrm{b}}$ The probability of retention is 0.6 by 12 months and 0.46 by 25 months in care

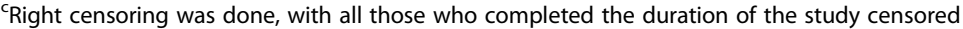

for any of them. So, we both came here, and we were both found to be HIV positive. This made it very easy for me because we were counselled together as a couple" 32-year-old, retained woman.

Other facilitators reported included desire to stay alive and raise HIV-negative babies.

\section{Barriers of option B+ initiation}

Patient unreadiness, inadequate counselling, HIV-related stigma and unsupportive partners and drug side-effects were the issues highlighted mostly by the women, especially those that were LTFU.

"I was not ready, as soon I tested positive, I was given medicines and was told to swallow them. I asked the health worker for time to think about it, but they said I had to start the medicines immediately. Other people I had heard about started with Septrin but for me I was started on ARVs immediately." 23-year-old, LTFU.

HIV related stigma was another barrier. Some women feared discrimination and labeling of their children if their HIV status was known and thus felt the need to protect their children.

"I had the fear of coming to the health facility because I feared meeting my friends here. I would wonder how to fit in society where people knew that I was HIV positive. I feared that they would segregate against my other children, though they were HIV negative" 26year-old, LTFU.

\section{Facilitators of adherence to clinic visits}

One mother reported overcoming her daily hassles by better planning and keeping appointments by setting reminders in her phone and memorizing the upcoming appointment date.

"I have daily work such as farming, cooking would stand in the way of my appointments, but I would just overcome them by better planning such as waking up very early in the morning at $5 \mathrm{am}$ and take the cows to the bush for feeding, cook food early before I leave such that by 8am, I am done with all the home chores and I would be in time for my health facility appointment.

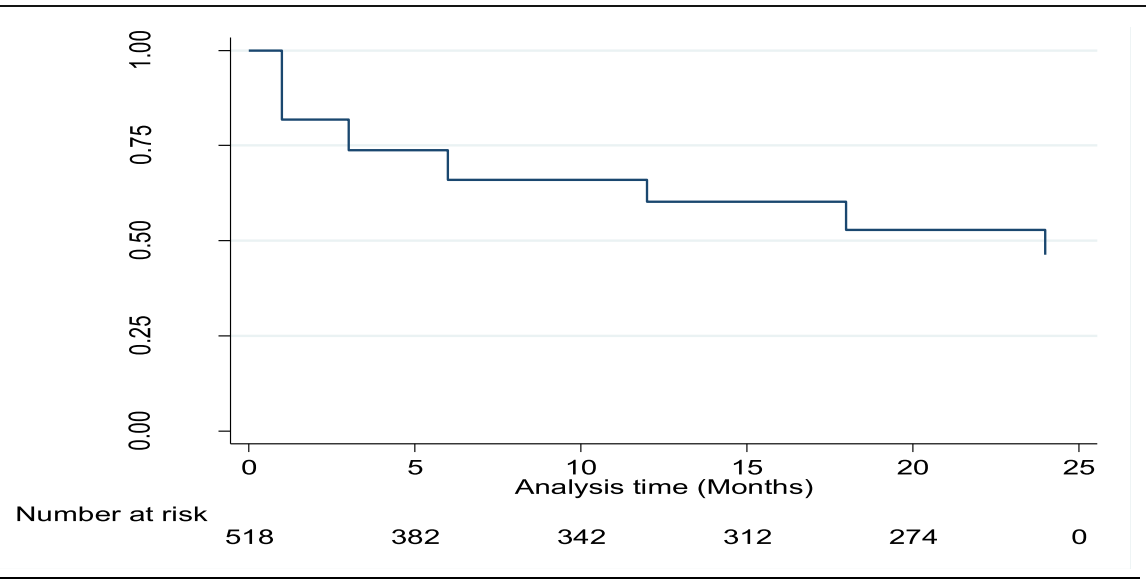

Fig. 2 Kaplan Meier for probability of retention over 25 months of follow up 


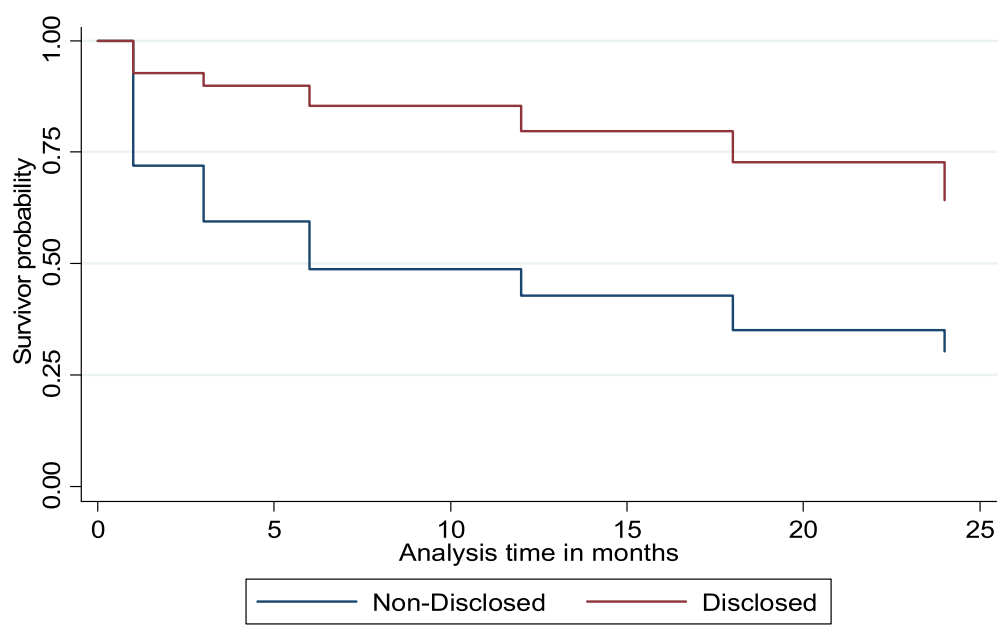

Fig. 3 Kaplan Meier showing retention estimates by disclosure status

On the day of appointment, I don't go for digging. $I$ would remind myself by memorizing and checking my appointment book" 27-year-old, retained.

Another mother who was retained in care reported that the only reason she managed to stay in care was because she overcame the fear of the negative consequences of disclosure, and she told her spouse about her status and noted that his positive attitude and support helped her adhere to her clinic visits. She however reports that despite his support, he refused to test for HIV, claiming to be immune to the virus.

"At delivery of the baby, I made up my mind to disclose, and I braced myself for being chased away from home after disclosure. I told him and to my surprise, he said that it was okay and started supporting me. Today he is the one who reminds me to take my $A R V$ s, though for him he says he is immune to the HIV virus and refused to come for testing. Many women are hiding their status from the partners, I encourage them to disclose their status because the experience of living with a supportive partner is needed if one is to have successful care in Option B+" 28-year-old, retained.

The desire to stay alive was also a strong motivation for mothers to adhere to their care and clinic visits. For most, this was because they wanted to raise their children and see them become independent.

"I was looking for a healthy life, so that I can live and raise my children. If I don't take my medicine, I will fall ill and die, and no one will take care of my children" 27-year-old, retained.

\section{Barriers of adherence to clinic visits}

Side effects were mentioned by all the women who were retained and those who were LTFU. One mother reported that she felt like the side effects of the medicines were going to kill her, so she opted to drop out of care to live a better-quality life.

"The medicines used to give me a lot of side effects and when I talked to the health workers to change my medicines, they said that I would eventually get used to it, I tried but it became too much, and I stopped. I couldn't get out of bed, I was sleepless at night and I felt like it was going to kill me even before the HIV/ AIDS, so I decided to stop" 20-year-old, LTFU.

Failure to develop coping strategies was mentioned by about $75 \%$ percent of the women who were LTFU. A young mother reported that she had to choose between her employment, her studies and keeping her appointments. She chose the job because she needed the money, and she dropped both out of Option B+ care and school.

"I was trying to complete my Senior 4 at the time, and I also had to start working to get some money to keep me going. At the salon where I was working, the boss wanted me to work 7 days a week and if I did not work, I would not be paid. I failed to get around this because of the needs I had. My school and work were overwhelming, eventually I had to drop out of school as well, and I did not sit for my O-level exams." 20year-old, LTFU.

Lack of spousal support, coupled with violence and abandonment was another main reason for LTFU. One mother reported that her boyfriend, who had promised to stay with her for life abandoned her when she told 
Table 4 Crude and adjusted hazard ratios (HRs) of LTFU in HIV care for Option B+ by socio-demographic characteristics and enabling resources

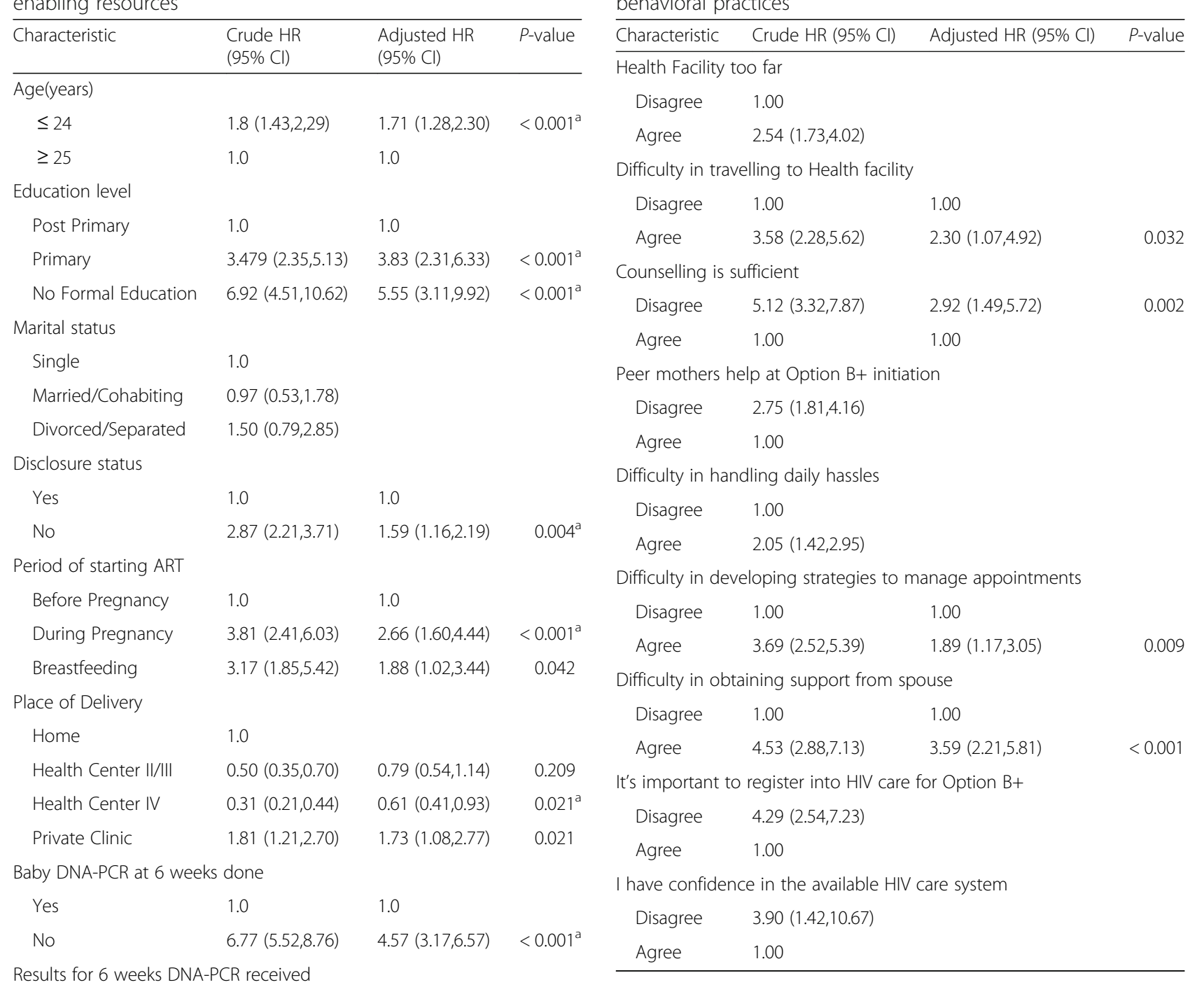

Table 5 Crude and adjusted hazard ratios (HRs) of LTFU in HIV care for Option B+ by attitudes, perceptions and personal behavioral practices

Peer mothers help at Option B+ initiation

$$
5(1.81,4.16)
$$

ifficulty in handling daily hassles

Difficulty in developing strategies to manage appointments

$$
\begin{array}{lll}
\text { Yes } & 1.0 & 1.0
\end{array}
$$$$
\text { No } \quad 2.41(1.43,4.09)
$$

Final Status of child

$$
\begin{array}{cc}
\text { Positive } & 1.0 \\
\text { Negative } & 1.88(1.17,3.04) \\
\text { Income/Monthly (Uganda Shilling) } \\
<50,000 & 3.32(1.35,8.19) \\
50,001-100,000 & 2.29(0.86,6.12) \\
>100,000 & 1.00
\end{array}
$$$$
\begin{array}{llll}
\text { Negative } & 1.88(1.17,3.04) & 1.18(0.63,2.20) & 0.602
\end{array}
$$

Distance from health facility

$$
\begin{array}{ll}
<1 \mathrm{~km} & 1.00 \\
1-5 \mathrm{~km} & 1.67(0.77,3.67) \\
>5 \mathrm{~km} & 3.48(1.57,7.69)
\end{array}
$$

${ }^{\mathrm{a} S o c i o-d e m o g r a p h i c}$ predictors of retention in care for women under Option B+ him about her HIV positive status. She felt purposeless and dropped out of care.
"I think I would have tried to stay in care if I had some form of support from my boyfriend. He had promised me that we would be together all our lives, the moment he got to know about my status, he changed. This made me very sad and I couldn't keep on coming for my appointments because I felt it was purposeless" 20-year-old, LTFU.

\section{Discussion}

We conducted a study that was a combination of a retrospective cohort analysis and cross-sectional study, investigating retention in care for pregnant and 
breastfeeding women on Option $\mathrm{B}+$ that were enrolled in care between March 2013 and March 2015, in Gomba district. We found that health facility retention was $60.2 \%$ at 12 months and $46.3 \%$ at 25 months. However, retention after contact tracing was 10\% higher with many women found to have simply transferred to other health facilities. Nearly $50 \%$ of women were not traceable, mainly due to lack of contact details. There is a need to establishment a tracking system with reliable contact information and unique identifiers for example through the use of the recently introduced National Identity cards [27, 28]. The main predictors of retention were maternal age, level of education, counselling, disclosure status, timely DNA/PCR testing at 6 weeks and ability to develop strategies to keep appointments. The major facilitators for Option $\mathrm{B}+$ initiation were adequate counselling, disclosure and spousal support, and the desire to stay alive and raise HIV-free children. Drug side effects, inadequate counselling and patient non-readiness, stigma, and un-supportive spouse were among the major barriers to the initiation of lifelong ART. Among the facilitators of adherence to clinic visits, ability to develop strategies to address daily hassles, ability to obtain spousal/family support, and disclosure were the most prominent. The barriers to adherence that were mentioned mostly by both retained and LTFU mothers included, drug side effects, failure to develop strategies to overcome daily hassles, lack of spousal support, and non-disclosure. Several of these barriers are modifiable and could be minimized through adequate counseling and support to enhance preparedness and planning to improve retention.

\section{Retention in care for pregnant and breastfeeding women}

The overall facility retention in care at 25 months, of $46.3 \%$ and all other time points was lower than that observed in a study done in northern Uganda [29] and in Malawi [12]. The true retention at $71.3 \%$ was similar to what was found in Malawi, in a setting that had electronic medical records system to track self-transfers [14]. High facility LTFU may be explained by poor follow up of women who are LTFU in rural, resource constrained facilities. In rural health facilities, health workers are not motivated enough to be vigilant about LTFU women, as it was found by Kallander [30-33]. It is also noteworthy that about half of the women had no phone or physical contact information, and some had incorrect contact details, which makes any attempt to follow them up virtually impossible. Ensuring complete and accurate contact information is a critical area for intervention [34].

We found that $32.8 \%$ of the women were misclassified as LTFU in routine data, underestimating the true level of retention at 25-months. A systematic review and meta-analysis of interventions to improve PMTCT service delivery and promote retention in Tanzania showed that up to $54.4 \%$ of LTFU clients had self-transferred to another facility [35]. The lack of a unified database with unique identifiers to help track the patients across facilities is a major challenge to HIV care in general and PMTCT specifically [36].

The rate of health facility LTFU was highest between initiation of ART and the 6-month visit. This may be explained by the failure to navigate the complexity of decisions a woman must make such as immediate initiation on ART [16]. In the second year, a large proportion of women were LTFU around the 18 months period, the critical period of transfer from Option $\mathrm{B}+$ care point to adult care point. This could be explained by the poor health facility linkages between ART clinics and Option $\mathrm{B}+$ care points, and the lack of desire by the mothers to stay on Option B+ once their baby is declared HIV negative [27, 37-40]. Studies have also highlighted the fear to be known as HIV positive and the stigma associated with HIV-only chronic care clinics. The integrated care within the ANC facilities masks the HIV status of the women, which is not possible once they transfer to the predominantly HIV chronic care clinics [41]. This highlights the need to explore integrated service and other models of chronic care for HIV infected pregnant and breast feeding women to minimize LTFU.

Women of a younger age of $<25$ years with older spouses had more challenges with retention in care possibly because of their lack of independence from their spouses about decision making, and financial sustenance, which affects their ability to make decisions regarding their health $[14,42,43]$. Older women may have more settled lifestyles with less social pressures, which allow them to better cope with Option B+ care. Women with no or low formal education were also more likely to be LTFU in care possibly due to more challenges in appreciating HIV related information and schedules [43-47].

As documented in other studies, we found that adequate counselling was with a facilitator of retention in care $[29,43]$. Pregnant HIV infected women face complex decisions that require major lifestyle and work related adjustments to cope with motherhood and HIV care and thus require counseling and other support to cope [48]. During this transition, support from family and especially their spouses is also crucial to their coping. It is thus not surprising that the women who disclosed their HIV status to the male partners did much better than their counterparts who had not done so $[16,29,43]$. Women are also inclined to provide false contact information because of fear of stigma and discrimination [43]. As documented elsewhere, ability to develop strategies to overcome daily hassles and keep appointments was associated with retention in care [30-32]. 
Mothers whose babies were not tested for HIV at 6 weeks were more likely to be LTFU. Women who do not adhere to their own care schedules will likely also miss those for their infants $[29,49]$. A negative HIV test for the infant could also motivate the women to remain in care [37].

Drug side effects were a major barrier to adherence on Option $\mathrm{B}+$. This may be due to the decreased morale caused by the side effects. These findings are consistent with recent studies in Uganda, Malawi and Ethiopia [16, 40, 42].

\section{Study strengths and limitations}

. The use of qualitative methods allowed for explanatory depth to the quantitative methods. However, there were some limitations. About half of the women were not reached due to lack of contact information-as ably demonstrated through the tracking of women, there is gross underestimation of retention which most likely equally applies to those who were not tracked. Further, the data used was from routine care program records not designed for research purposes, and several desired variables, such as occupation, religion, income, perceptions about eMTCT services were missed during the cohort data abstraction. This was mitigated by tracking and interviewing the women for additional data. Some mothers who were interviewed had to give information on events as far back as 2013, with possibility of recall bias.

\section{Conclusions}

Generally, LTFU was high especially in the first 6 months and during the 12-18-month period (at the time of transfer to chronic care) and was especially more pronounced among the young women with low educational status and those who had not disclosed their HIV status to their partners. Retention in care was also under-estimated at health facility level. Interventions to enhance PMTCT should focus on improving tracking of women across facilities, such as the use of an online electronic medical records system to automatically track self-transfers, and improving counseling and support for disclosure especially among young women and those with low education status.

\section{Abbreviations}

ANC: Antenatal Care; ART: Antiretroviral Therapy; EMOC: Emergency Obstetric care services; EMTCT: Elimination of Mother to Child Transmission; HIV: Human Immunodeficiency Virus; LTFU: Loss-to-follow-up; PMTCT: Prevention of Mother to Child Transmission; WHO: World Health Organization

\section{Acknowledgements}

The authors thank the Gomba district EMTCT cohort participants and study staff whose contributions made this work possible.

\section{Funding}

This study was partly funded by the Makerere University School of Public Health, the Supporting Policy Engagements for Evidence-based Decisions (SPEED) for Universal Health Coverage Project, and The Ugandan Academy for Health Innovation and Impact. The Ugandan Academy is initially funded by Janssen, the Pharmaceutical Companies of Johnson \& Johnson as part of its commitment to global public health through collaboration with the Johnson \& Johnson Corporate Citizenship Trust.

\section{Availability of data and materials}

The dataset used and analyzed during this study is available from the corresponding author upon request.

\section{Authors' contributions}

GK participated in designing the study, data collection, and statistical analyses and served as the lead author of the manuscript. FM, FO, MO, and BC participated in study conception and interpretation of results. RW and NK played active roles as supervisors during all stages of the study as well as manuscript writing. JN participated in qualitative data analysis and interpretation of results. All the authors read and approved the final manuscript.

\section{Ethics approval and consent to participate}

Ethical approval to conduct this study was granted by the Higher Degrees Research and Ethics Committee (HDREC) of the Makerere University School of Public Health and the Uganda National Council of Science and Technology (UNCST). Permission was also obtained from the District Health Officer (DHO). Routine service data was anonymized for analysis. Participants in the cross-sectional quantitative and qualitative interviews provided written informed consent prior to the interview.

\section{Consent for publication}

Not applicable.

\section{Competing interests}

The authors declare that they have no competing interests.

\section{Publisher's Note}

Springer Nature remains neutral with regard to jurisdictional claims in published maps and institutional affiliations.

\section{Author details}

${ }^{1}$ Department of Health Policy Planning and Management, Makerere University School of Public Health, P.O Box 7072, Kampala, Uganda. ${ }^{2}$ Department of Epidemiology and Biostatistics, School of Public Health, Makerere University College of Health Sciences, Kampala, Uganda. ${ }^{3}$ Department of Disease Control and Environmental Health, Makerere University School of Public Health, Kampala, Uganda. ${ }^{4}$ Department of Research, Infectious Diseases Institute, Makerere University College of Health Sciences, Kampala, Uganda.

Received: 19 February 2018 Accepted: 16 October 2018 Published online: 24 October 2018

\section{References}

1. UNAIDS, "Start Free, Stay Free, AIDS Free - A super-fast-track framework for ending AIDS among children, adolescents and young women by 2020," 2016. [Online]. Available: http://www.unaids.org/sites/default/files/media_ asset/Stay_free_vision_mission_En.pdf. Accessed 02 Oct 2017.

2. UNAIDS, "Fact sheet 2016 | UNAIDS," UNAIDS, 2016. [Online]. Available: http://www.unaids.org/en/resources/fact-sheet. Accessed 02 Oct 2017.

3. WHO, "Progress Report 2016, prevent HIV, test and treat all," 2016.

4. IATT, "Monitoring \& evaluation framework for antiretroviral treatment for pregnant and breastfeeding women living with HIV and their infants," 2015.

5. Hassinger R. Uganda Adopts New PMTCT Strategy, Option B +. 2015. Retrieved October 22, 2018 from https://www.msh.org/comment/8467.

6. MoH, "National Health Care Waste Management Plan 2009/10-2011/12." [Online]. Available: http://webcache.googleusercontent.com/search?q= cache:yl_5Jgg6YFUJ:library.health.go.ug/download/file/fid/1095+\&cd=4\&hl= en\&ct=clnk\&gl=ug. [Accessed: 16 Aug 2018].

7. Rollins NC, et al. Defining and analyzing retention-in-care among pregnant and breastfeeding HIV-infected women: unpacking the data to interpret 
and improve PMTCT outcomes. J Acquir Immune Defic Syndr. 2014;67 S150-6

8. Sam-Agudu NA, et al. The impact of mentor mother programs on PMTCT service uptake and retention-in-care at primary health care facilities in Nigeria: a prospective cohort study (MoMent Nigeria). J Acquir Immune Defic Syndr. 2014:67(Suppl 2):S132Á8.

9. WHO, "Retention in HIV programmes. Defining the challenges and identifying solutions," 2012

10. Nachega JB, et al. Adherence to antiretroviral therapy during and after pregnancy in low-income, middle-income, and high-income countries: a systematic review and meta-analysis. Aids. 2012;26(16):2039-52.

11. Kohler PK, et al. Community-based evaluation of PMTCT uptake in Nyanza Province, Kenya. PLoS One. 2014;9(10):e110110.

12. Tenthani $L$, et al. Retention in care under universal antiretroviral therapy for HIV infected pregnant and breastfeeding women ('Option B+') in Malawi. AIDS. 2014;28(4):589

13. ElizabethGlazerFoundation, "Treatment for Life, Part 1: Option B+ Gives Mothers and Children Options," 2016. [Online]. Available: http://www. pedaids.org/blog/entry/treatment-for-life-part-1-option-b-gives-mothersand-children-options. Accessed 22 Sept 2018.

14. Haas $A D$, et al. Retention in care during the first 3 years of antiretroviral therapy for women in Malawi's option B+ programme: an observational cohort study. Lancet HIV. 2014;3(4):e175-82.

15. Sibanda EL, Cowan FM. Good news for retention of women on option B+ in Malawi. Lancet HIV. 2016;3(4):e151-2.

16. Buregyeya $\mathrm{E}$, et al. Facilitators and barriers to uptake and adherence to lifelong antiretroviral therapy among HIV infected pregnant women in Uganda: a qualitative study. BMC Pregnancy Childbirth. 2017;17(1):94.

17. Nabukeera-Barungi $\mathrm{N}$, et al. Adherence to antiretroviral therapy and retention in care for adolescents living with HIV from 10 districts in Uganda. BMC Infect. Dis. 2015;15(1):520.

18. UBOS. National Population and Housing Census 2014. In: Uganda Bur. Stat. 2016, Natl. Popul. Hous. Census 2014 - Main Rep. , Kampala, Uganda; 2014 p. 1-209.

19. WHO, "Fact sheet on the Uganda Population HIV Impact Assessment | WHO | Regional Office for Africa," 2017. [Online]. Available: https://www.afro.who. int/publications/fact-sheet-uganda-population-hiv-impact-assessment. [Accessed: 16 Aug 2018].

20. MoH, "Uganda Demographic and Health Survey Report 2016 | Knowledge Management Portal," 2017. [Online]. Available: http://ibrary.health.go.ug/ publications/leadership-and-governance-monitoring-and-evaluation/ statistics/uganda-demographic-and. [Accessed: 16 Aug 2018].

21. Hamilton E, et al. Using the PMTCT Cascade to accelerate achievement of the global plan goals. JAIDS J. Acquir. Immune Defic. Syndr. 2017;75:S27-35.

22. M. Mason, "Sample size and saturation in PhD studies using qualitative interviews," in Forum qualitative Sozialforschung/Forum: qualitative social research, 2010, vol. 11, 3 .

23. StatsToDo, "StatsToDo : Sample Size for Survival (Kaplan Meier Log Rank Test) Program." [Online]. Available: https:/www.statstodo.com/SSizSurvival_ Pgm.php. Accessed 22 Sept 2018

24. Kieffer MP, et al. Lessons learned from early implementation of option B+: the Elizabeth Glaser Pediatric AIDS Foundation experience in 11 African countries. JAIDS J Acquir Immune Defic Syndr. 2014:67:S188-94.

25. Clouse $\mathrm{K}$, et al. Patient retention from HIV diagnosis through one year on antiretroviral therapy at a primary healthcare clinic in Johannesburg, South Africa. J. Acquir. Immune Defic. Syndr. 2013;62(2):e39.

26. Braun V, Clarke V, Terry G. Thematic analysis. Qual Res Clin Heal Psychol. 2014:95-114.

27. Helova A, et al. Health facility challenges to the provision of Option B+ in western Kenya: a qualitative study. Health Policy Plan. 2016;32(2):Czw122.

28. F. Cataldo, et al. She knows that she will not come back: tracing patients and new thresholds of collective surveillance in PMTCT Option B. BMC Health Serv. Res. 2018;18(1):76.

29. Obai G, Mubeezi R, Makumbi F. Rate and associated factors of non-retention of mother-baby pairs in HIV care in the elimination of mother-to-child transmission programme, Gulu-Uganda: a cohort study. BMC Heal. Serv Res. 2017;17(1):48.

30. Kallander $\mathrm{K}$, et al. Inscale cluster randomized trial evaluating the effect of innovative motivation and supervision approaches on community health worker performance and retention in uganda and mozambique: Intervention design. Am. J. Trop. Med. Hyg. 2012;1:243.
31. Bonenberger M, Aikins M, Akweongo P, Wyss K. The effects of health worker motivation and job satisfaction on turnover intention in Ghana: a crosssectional study. Hum Resour Health. 2014;12:43.

32. Mathauer I, Imhoff I. Health worker motivation in Africa: the role of nonfinancial incentives and human resource management tools. Hum Resour Health. Aug. 2006:4:24

33. Thi Hoai Thu N, Wilson A, McDonald F. Motivation or demotivation of health workers providing maternal health services in rural areas in Vietnam: findings from a mixed-methods study. Hum. Resour. Health. 2015;13(1):91.

34. McMahon JH, Elliott JH, Hong SY, Bertagnolio S, Jordan MR. Effects of Physical Tracing on Estimates of Loss to Follow-Up, Mortality and Retention in Low and Middle Income Country Antiretroviral Therapy Programs: A Systematic Review. PLoS One. 2013;8(2):e56047.

35. Ngarina $\mathrm{M}$, et al. Women's preferences regarding infant or maternal antiretroviral prophylaxis for prevention of mother-to-child transmission of HIV during breastfeeding and their views on Option B+ in Dar es Salaam, Tanzania. PLoS One. 2014;9(1):e85310.

36. Rawizza HE, et al. "Loss to Follow-Up within the Prevention of Mother-to-Child Transmission Care Cascade in a Large ART Program in Nigeria." 2015;13(3):201-09.

37. Kalembo FW, Zgambo M. Loss to Followup: a major challenge to successful implementation of prevention of mother-to-child transmission of HIV-1 programs in sub-Saharan Africa. ISRN AIDS. 2012;2012:1-10.

38. Herce ME, et al. Supporting Option B+ scale up and strengthening the prevention of mother-to-child transmission cascade in central Malawi: results from a serial cross-sectional study. BMC Infect. Dis. 2015;15(1):328.

39. Gamell A, et al. Prevention of mother-to-child transmission of HIV Option B + cascade in rural Tanzania: The One Stop Clinic model. PLoS One. 2017; 12(7):e0181096

40. Flax VL, Hamela G, Mofolo I, Hosseinipour MC, Hoffman IF, Maman S. Factors influencing postnatal Option B+ participation and breastfeeding duration among HIV-positive women in Lilongwe District, Malawi: A qualitative study. PLoS One. 2017;12(4):e0175590.

41. Valenzuela C, et al. HIV stigma as a barrier to retention in HIV care at a general hospital in Lima, Peru: a case-control study. AIDS Behav. 2015;19(2):235-45.

42. Mitiku I, Arefayne M, Mesfin Y, Gizaw M. Factors associated with loss to follow-up among women in Option B+ PMTCT programme in northeast Ethiopia: a retrospective cohort study. J. Int. AIDS Soc. 2016;19(1).

43. Tweya $\mathrm{H}$, et al. Understanding factors, outcomes and reasons for loss to follow-up among women in option B+ PMTCT programme in Lilongwe, Malawi. Trop Med Int Heal. 2014;19(11):1360-6.

44. Rachlis B, et al. Facility-level factors influencing retention of patients in HIV care in East Africa. PLoS One. 2016;11(8):e0159994.

45. Ebuy $\mathrm{H}$, Yebyo $\mathrm{H}$, Alemayehu M. Level of adherence and predictors of adherence to the option B+ PMTCT programme in Tigray, northern Ethiopia. Int J Infect Dis. 2015;33:e123-9.

46. Gugsa $\mathrm{S}$, et al. Exploring factors associated with ART adherence and retention in care under Option B+ strategy in Malawi: A qualitative study. PLoS One. 2017:12(6):e0179838.

47. Hoffman RM, et al. Factors associated with retention in Option B+ in Malawi: a case control study. J. Int. AIDS Soc. 2017;20(1):21464.

48. Stinson K, Myer L. Barriers to initiating antiretroviral therapy during pregnancy: a qualitative study of women attending services in Cape Town, South Africa. African J AIDS Res. 2012;11(1):65-73.

49. Ambia J, Mandala J. A systematic review of interventions to improve prevention of mother-to-child HIV transmission service delivery and promote retention. J Int AIDS Soc. 2016;19(1):20309.

\section{Ready to submit your research? Choose BMC and benefit from:}

- fast, convenient online submission

- thorough peer review by experienced researchers in your field

- rapid publication on acceptance

- support for research data, including large and complex data types

- gold Open Access which fosters wider collaboration and increased citations

- maximum visibility for your research: over $100 \mathrm{M}$ website views per year

At $\mathrm{BMC}$, research is always in progress.

Learn more biomedcentral.com/submissions 